\title{
How might teachers enable learner self-confidence? A review study
}

\author{
Professor Effie Maclellan, \\ School of Education, \\ Faculty of Humanities, Arts and Social Sciences, \\ University of Strathclyde, \\ Glasgow, G4 0LT \\ E-mail: e.maclellan@strath.ac.uk \\ Telephone: 01414448064
}




\title{
How might teachers enable learner self-confidence? A review study
}

\author{
Abstract \\ In the context of learner-centred learning and curricular reform, self-confidence is invoked as an important \\ construct. However, there is no easily available research-informed guidance on what self-confidence means \\ for the professional teacher. This study uses the analytic technique of Concept Analysis to review \\ psychology and education literatures to provide a 'take-home' message for teachers. The review identifies \\ conceptual artefacts (ideas, theories, concepts which explain, connect, predict or apply knowledge) that the \\ teacher can appropriate in order to enable learner self-confidence. These conceptual artefacts are classified \\ in three groups: characterising self-confidence; self-judgements of confidence; and factors that influence \\ the development of self-confidence. The review finds self-confidence to be a robust and stable \\ psychological construct, best promoted through teachers' attention to learners' development of knowledge \\ and engagement in socially designed learning activities. It further finds that teachers' attention to activities \\ which involve learners' self-regulation are of importance.
}

\section{Keywords}

Self-confidence; metacognition; psychology; educational achievement; conceptual artefacts

\section{Introduction}

Our capacity for reflexive thought means that we are able to think about how others see us and who we are. Reflexive thought is increasingly being understood as necessary in the current climate of education curricula reform in EU countries (European Commission 2012) where the emphasis is less on transmitting knowledge and skills (important as these are) and more on promoting autonomous and agentic learning (Goldstone and Day 2012; Lüftenegger et al. 2012; Zimmerman 2008). This consciousness of our own identity - our self - is possibly our most important possession (Kristjánsson 2010). Sedikides and Gregg (2007) define the self as "the totality of interrelated yet distinct psychological phenomena that underlie, causally interact with, or depend upon reflexive consciousness" (p. 93). The self is not some static entity but rather a complex set of properties and processes through which we infer the veracity of our judgements (Kruglanski 1990). Thus there are many labels (sometimes with overlapping meaning) used in relation to the self: attribution, concept, control, efficacy, esteem, regulation and so on (Skinner 1996) which are used to account for the responsiveness of the self to the social contexts in which we find ourselves. The centrality of the self in learning is acknowledged in curricular reforms in countries across Europe (Europa 2006) implying confidence in oneself to be a fundamental competency. As such, self-confidence is invoked as an important psychological construct both in understanding human behaviour and in engendering well-being. 
However, the Education literature is thin in its discussion of what self-confidence is or might be. Referred to largely as 'a good thing', self-confidence seems to be some ethereal capacity which persons apparently 'lose' or 'gain'. Put plainly teachers need, but cannot readily access, conceptual knowledge of what self-confidence is. They further need exemplification of how self-confidence can be promoted. Equipped with these two sets of knowledge, they can then use this knowledge, adaptively, to respond to learners in their care. But exhorting teachers to promote self-confidence, on the assumption that the construct has uncontested meaning (Craig 2007), is insufficient when teachers need a coherent body of knowledge with which to theorise about self-confidence for the benefit of learners (Deng 2004). In order that they can theorise (and thereby make reasoned and informed decisions as to particular 'best practices' in particular pedagogical situations) teachers need to have at their disposal appropriate conceptual artefacts (Bereiter 2002). Conceptual artefacts are theories, hypotheses, factual claims, myths and ideas; all of which can be regarded as knowledge and which, therefore, are both subject to revision and discussable. Their value lies in their power to explain, connect, predict or apply knowledge in one situation to illuminate another. Teachers are not alone in seeking to use conceptual artefacts in the service of novel social practices (Hakkarainen 2009) which, in their case, is the improvement of others' learning, necessitating teacher reflection on their own models of learning (Strauss 1993).

While the Education literature is thin in its documentation of how teachers might think about self-confidence, the Psychology literature has a long history of documenting selfconfidence (Stankov and Kleitman 2008). Studies therein typically characterise confidence as responses to prompts such as, "Are you sure your answer is correct?" and measure it as a correlation of objective accuracy and individual 'sureness'. Theoretically different explanations of confidence judgements offer valuable insights but fragment on the issue of whether judgements are a function of psychological factors within the person or ecological factors external to the person (Kleitman 2008). As the empirical evidence points to self-confidence being both trait-like (implying relative stability over time) and domain-specific (implying a context-dependant dynamic) (Stanovich and West 1998, 1999, 2000), this article will search psychologically-informed literature to provide a take-home message of what is important for professional teachers to understand about self-confidence in relation to educational achievement. Specifically, the question being addressed is: How might teachers enable learner self-confidence? 


\section{Method}

The current press in Education, to base provision on demonstrably effective practices, demands a knowledge base which is broad in perspective and which recognises the contested ideas inherent in many 'effective practices'. Describing and explaining the current knowledge which might guide professional practice is a purpose well-served by a literature review (Fink 2010). Within the spectrum of methodological design for literature reviews, the particular form chosen is a Narrative Synthesis. It is posited as being systematic insofar as it:

- has a stated aim and review questions

- identifies inclusion criteria

- conducts a search for studies

- $\quad$ screens studies

- is explicit in its data analysis

- synthesises results (Andrews and Harlen 2006)

Because the concern of this paper was the paucity of Education literature around the topic of self-confidence in relation to formal education, the search term was self-confidence qualified by cognitive/academic achievement. Related 'self' terms were not used as they would have generated both an unmanageably large number of publications and detracted from the focus of the study. Databases searched were WEB OF Knowledge, Google Scholar, Scopus, PsycARTICLES and ERIC. The time lapse (2002-2012) was to some extent arbitrary but it also captured current and up-to-date studies. In addition to database searches, snowball searches yielded further possibilities. From a total of more than 300, a final corpus of 104 studies was selected. The studies had been conducted mostly in the USA and the EU countries with fewer than 20 having been conducted in Asian and far Eastern countries. To be included, studies had to:

- Offer an empirical or theoretical analysis; and, in the case of empirical studies, samples had to include participants in formal education.

- Be peer-reviewed manuscripts/book chapters to signify the scholarly nature of the review. Review articles per se were candidates for inclusion, as were qualitative and quantitative studies

- Have a recognisable design, appropriate to an empirical or theoretical analysis

- Be written in English

- Report on/theorise about the correlates/predictors of self-confidence, rather than merely 'mentioning' self-confidence as an adjunct or afterthought 
All papers which met these criteria were analysed using the technique of Concept Analysis. This type of analysis considers concept definitions and related constructs, the empirical substantiation for the concepts and the use of the concept in practical situations (Tofthagen and Fagerstrøm 2010). Reviewed papers are reported in three broad thematic groupings: characterising self-confidence (clarifying a phenomenon in sets of words to expose what it means or might mean); self-judgements of confidence (the empirical substantiation for the concepts); and factors that influence the development of self-confidence (the use of the concept in practical situations). Organised in this way, the review thus offers conceptual clarification of the nature and validity of Self-Confidence before illustrating how it can be promoted. The technique of Concept Analysis strives to be impartial but the influences of personal epistemological beliefs on interpretation are acknowledged (Maggioni and Parkinson 2008).

\section{Characterising Self-Confidence}

Self-confidence is contextualised within domain-specific and person-specific self-views. Because of a fundamental need to evaluate our opinions and abilities and because such judgements cannot be objectively determined, we use others' views of us to inform our own self-views. Even if our self-views are by some objective criterion chronically misconceived (Ehrlinger and Dunning 2003), the tendency to construct concepts of self as consistent (Koriat 2012) will obtain. The views that each holds of self may also play out in quite contradictory ways and explanations of difference are attributed, in part, to the differences in confidence with which persons hold their self-views (Briñol, DeMarree, and Petty 2010). Views of self are conceptualised in constructs such as esteem, concept and efficacy. The relationship between self-confidence and self-esteem is unclear, with the literature offering confusing and contradictory messages (Story 2004; Baumeister 2005; Ferkany 2008). However, the term selfesteem is regularly conflated with self-concept. Kröner and Biermann (2007) argue that selfconfidence judgements are influenced by self-concept; reasoning that since self-concept represents self-perceived competence in various domains (thereby including individuals' knowledge about extant skills and abilities), it is this knowledge which individuals bring to bear when asked to judge response confidence. Thus, in situations in which persons have no idea of the objective accuracy of their responses, they rely on their self-concept - on how they perceive 'usual' performance. Further, the clarity of their self-concept - the extent to which self-beliefs are clearly defined, consistent and stable - has implications for subsequent behaviour (Story 2004). Those whose self-concept is less clear are prone to greater self-handicapping behaviour (Thomas and Gadbois 2007); implying the desirability for improved self-concept clarity. Both non- 
academic self-concept (Shi, Li, and Zhang 2008) and academic self-concept for Mathematics, English and memory/reasoning tasks (Kleitman and Stankov 2007; Stankov and Lee 2008; Lee 2009; Stankov, Lee, et al. 2012) have promoted self-confidence.

Closely related to self-concept is self-efficacy (Bong and Skaalvik 2003), largely because perceived competence is the principal constituent of both. Self-efficacy is the individual expectation that persons can execute the behaviour required to produce a declared outcome. Self-efficacy is noted as a situationally-specific manifestation of confidence (Block et al. 2010), and is amenable to intervention (Cramer, Neal, and Brodsky 2009; Putwain, Sander, and Larkin 2012). Given the centrality of self-efficacy to academic achievement (Prat-Sala and Redford 2011), it is important to note that, without pro-active intervention, self-efficacy can decline over time with concomitant deterioration in academic achievement (Caprara et al. 2008). Self-concept and self-efficacy are, however, empirically distinct (Ferla, Valcke, and Cai 2009; Lee 2009) with self-concept impacting on self-efficacy.

\section{Implications of what Self-Confidence is}

A preliminary foray into the meaning of self-confidence exposes it as a belief or view that each person has of self. It is a dimension of every individual's self-representation which will play out in a range of performance indicators and is associated with the individual's impression of his/her competence in a specific domain, context or situation. This being so, it will be referenced in both internal and external factors (Marsh et al. 2006). It is important for teachers to recognise that learner self-concept comprises academic and non-academic elements, and that while selfconcept can affect achievement, it is also susceptible to contextual and environmental features. Teachers who enable learners to make adaptive attributions for 'success' and 'failure' in learning, who include opportunity for the mastery of curriculum content, and who incorporate meaningful choice and involvement in learning activities are promoting positive self-beliefs (Valentine, DuBois, and Cooper 2004), and thereby supporting the development of healthy self-concept. Thus the support and development of self-concept with all that that means for increasing competence (Brunner et al. 2010) is an important cue for teachers who seek to improve learner self-confidence.

\section{Self-Judgements of Confidence}

While two learners might have the same belief or idea, one might have considerably greater certainty in that belief or idea than the other. It is the greater certainty that impacts on the judgment made. Beliefs alone are insufficient for impact: rather there needs to be some certainty 
assigned to the belief (Briñol, DeMarree, and Petty 2010). Evaluating one's beliefs for their validity is known as self-validation (Petty, Briñol, and Tormala 2002). Because the subjective experience of one's own beliefs is at a metacognitive level, the certainty/doubt assigned to such beliefs (the dynamic monitoring of 'online' thinking) is referred to as metacognitive confidence and is significant in academic achievement (Petty et al. 2007; Kleitman and Moscrop 2010). Learners' judgements of certainty in their beliefs are important to the teacher as these are needed to support problem solving, to promote group cohesion and to persuade others to one's point of view (Alexander et al. 2002; Briñol and Petty 2009).

There is extensive evidence for miscalibration (Soll and Klayman 2004; Koriat 2008). If judgement of accuracy is lower than objective accuracy, the miscalibration represents underconfidence. Underconfidence may mean that learners (inappropriately) doubt their own internal resources (such as ability, talent, skill, endurance and resourcefulness) or external resources (such as equipment, guidance, working conditions, or starting point) to effect a task successfully (Stirin et al. 2012). If judgement of accuracy is higher than objective accuracy, the miscalibration indicates overconfidence (Puncochar and Fox 2004; Moore and Healy 2008) with children's overconfidence being more pointed than adults' (Roebers 2002). Overconfidence is of concern. If learners believe that they 'know it all' and see no need to improve, they are less motivated to study and spend less time studying than are those whose objective accuracy is higher (Dunlosky and Rawson 2012).

However, overconfidence is more nuanced than previously outlined. Overconfidence can mean overestimation (judging ability to be superior to actual ability), overplacement (believing self to be better-than-average) or overprecision (expressing excessive certainty in response accuracy); manifestations which are regularly conflated (Moore and Healy 2008). The evidence for these conceptually and empirically distinct manifestations suggests that there is little to be gained from comparing ourselves with others: not only do we have incomplete and inaccurate knowledge about ourselves but we have even less complete or accurate knowledge about others. So even if one believes oneself to be better at a task, this does not irrefutably suggest that one is indeed more able. Burson, Larrick, and Klayman (2006) propose that miscalibration exists because estimates of performance are inexorably enmeshed in contextual 'noise', and because feedback on performance is highly variable. Overconfidence is thus a somewhat confounded construct. What matters is how learners engage with their own learning since there is evidence that confidence is influenced by factors such as thinking more frequently about thoughts and ideas, and increasing elaboration of thought (Petty et al. 2007). Rather than being concerned 
with alleged overconfidence, the design of opportunities for learners to engage in cognitively effortful activity would seem more productive.

Whether learners are 'over' or 'under' confident is not really the issue for teachers, since both appraisals are non-realistic and rooted in subjective feelings of competence (Larrick, Burson, and Soll 2007) which may be resistant to change (Koriat 2008, 2012). Rather, it is more important that the difference between confidence and accuracy be as near to zero as possible, thereby rendering a realistic appraisal of confidence (Stankov and Kleitman 2008). Enabling learners to be realistic is challenging because it requires the coordination of extant knowledge with judgements of its adequacy for a particular task; which invokes dimensions of self-efficacy, optimism and resilience (Stajkovic 2006). Realistic judgements can be supported by the teacher through making plain when ignorance is salient, thereby drawing attention to the need to update information (Pazy 2004), and through structuring situations that require learners to use the knowledge in problem solution (Hertzog, Price, and Dunlosky 2008).

Instructional methods and the specifics of the task interactively influence learner confidence (Boekaerts and Rozendaal 2010). Particularly, pedagogical interventions should make plain the epistemic authority of the target source of information since this influences its subsequent processing (Kruglanski et al. 2005). This means that it is important to challenge learners to marshal reliable, robust evidence in support of their beliefs and to avoid spurious consensus (Yaniv, Choshen-Hillel, and Milyavsky 2009; Koriat 2008). Learners need to develop their own epistemic authority such they do not need to rely, mindlessly, on the reported views of others who may be making judgements on fragile foundations (Mulnix 2012). To do otherwise is to risk leaving learners with false impressions of their competence.

The importance of realistic appraisal for agentic learning (Stankov, Lee, and Paek 2009) is in learners discriminating between contexts where they are sure of their abilities and those for which they recognise they are insufficiently equipped. It need do no harm to recognise that one's objective competence is insufficient for the task demands as self-doubt may trigger further cognitive effort (Woodman et al. 2010; Petty et al. 2007). Experiencing a task as difficult, anxietyprovoking, or satisfying together with perceptions of self-competence in different domains gives learners valuable information to inform subsequent behaviour (Efklides 2011). While chronic doubt can be debilitating and while our self-worth can be jeopardised if the only information we bring to our cognitive processing negates our sense of self (Sherman and Cohen 2006 ), doubt which stimulates further cognitive processing can be helpful. Such a proposition is quite nuanced, however. 
Doubt is perfectly normal when our own experiences of the world are incompatible with other representations of reality (Weary, Tobin, and Edwards 2010). When we receive messages which conflict with our personal views (mismatched messages) we may perceive them as uninteresting or irrelevant. Teachers are familiar with the paradoxical situation in which they make available new information; which is discounted by learners even although it would have enhanced learner understanding. However, when we receive a message which is consistent with our own value position, our own personal characteristics or our own psychological state (a matched message), we respond differently. Because matched messages are more personally relevant we engage in greater cognitive processing (Tormala, Rucker, and Segers 2008). When confronted by situations which trigger doubt, we need to harness additional cognitive resource with which to override defeatist attitudes, more technically known as ego-depletion (Hagger et al. 2010). There is thus a need to strengthen capacities to self-regulate, and thereby overtake/attenuate otherwise defensive responses (Loseman and Van Den Bos 2012). It is by learners drawing on self-affirmations (positive self-perceptions of growth, progress and optimism) rather than negative self-scripts (feelings of dread, anger, over-dependence on/overresponsibility for others, pessimism, cynicism, jealousy, self-pity) and by developing 'academic hardiness' (Kamtsios and Karagiannopoulou 2012) that they muster the confidence to approach tasks which are taking them 'out of their comfort zone'.

However, for teachers to support learner perseverance, they need to be substantively persuasive and genuine, rather than being gratuitously complimentary (Correll, Spencer, and Zanna 2004). Thus there is merit in teachers emphasising that the glass is 'half-full' rather than 'half-empty' but also in calibrating positive messages with knowledge of individual learners and their achievements. Further, because of the evidence for the ineffectiveness of both personpraise and blunderbuss praise, teachers need to confront the issues inherent in dialogic feedback (Yang and Carless 2012; Hattie and Gan 2011) such that they are sensitive to the interpersonal negotiation of feedback and to positioning learners as definitive sources of expertise in their own learning.

\section{Implications of Self-Confidence Judgements}

The evidence for how individuals judge their confidence strengthens the initial insight that confidence may be important to learners, and thus to teachers. It is clear that self-confidence is a robust and stable psychological construct (Kleitman and Stankov 2007; Stankov, Pallier, et al. 2012). Further it is clearly discernible in children as young as 9 years of age (Kleitman and Moscrop 2010) and derives from a range of cues and inferences (Mitchum and Kelley 2010). 
Self-confidence is closely related to abilities and knowledge in a given domain and is influenced by the amount of information retrieved, its vividness and target details. As well as the influence of domain knowledge, confidence is also affected by learners' beliefs about, and self-awareness of, general learning capabilities and strategies (Brewer, Sampaio, and Barlow 2005). For teachers to enable learner self-confidence, they must, themselves, be genuine and willing to engage learners in constructive discussion around the accuracy of learners' own judgements. Teachers are striving for as little difference as possible between learners' judgements of confidence and the objective accuracy of learner performance. Teachers therefore need to be explicit with learners about the doubt and ambiguity that surrounds many judgements, whilst also promoting academic hardiness. Teachers' own appreciation of self-confidence in all its nuances is therefore of importance.

\section{Factors Influencing the Development of Self-Confidence}

The first clutch of studies draws attention to the importance of emotional well-being in the development of self-confidence. Intervention programmes such as massage, relaxation and yoga therapy (Powell, Gilchrist, and Stapley 2008); positive-psychology interventions such as StrengthsQuest (Hodges and Harter 2005) and Positive Youth Development (Seevers, Hodnett, and Van Leeuwen 2011) contribute to improved self-confidence. Interventions which enable people to articulate their self-awareness and self-confidence of feelings appear to allow people to prepare for potential obstacles in the future (Guérin, Arcand, and Durand-Bush 2010). Indeed any situation which aims to improve social capital (such as service-learning, volunteering, customised learner-teacher conferences) can be seen to positively affect learner self-confidence John 2005; Grassi, Hanley, and Liston 2004; Risko and Walker-Dalhouse 2009; Usher and Pajares 2006).

Learners with a strong internal locus of control are better positioned in social and academic classroom situations to sustain goal-related behaviour, take personal responsibility for relationships with peers and adjust their behaviour to maintain and enhance the quality of these relationships (Garger, Thomas, and Jacques 2010). It appears that teachers who actively seek to build on what is already positive in their classrooms (and either abandon or eschew what doesn't promote previously negotiated and agreed goals) (Kelly and Bluestone-Miller 2009) are much better placed to support learners in outlining their own success and progress (Lloyd, Bruce, and Mackintosh 2012) which, in turn, is reported as improving confidence.

The importance of learner-learner and/or learner-teacher interactions for promoting selfconfidence is also noted. For example, computer-supported collaboration enables learners to 
appreciate dialogue as an important resource in learning (Jakobsson 2006; Park and Hyun 2006). Learners who have contact with their teachers outwith formal instruction, feel intellectually and emotionally more confident - with such confidence feeding back into formal instruction (Sax, Bryant, and Harper 2005). Not surprisingly the influence of peers perceived as credible or trustworthy - phenomena which are culturally laden (Van De Gaer et al. 2012) - encourages conformity (Horry et al. 2012; De Vries, Midden, and Bouwhuis 2003). But by 8 years-of-age, children can consider, and respond adequately to, subtle variations of social influence. With increasing years they become better at disregarding untrustworthy information and resisting conformity (Schwarz and Roebers 2006). What all of the programmes/interventions here seem to have in common - albeit expressed only implicitly - is a sense of the integrity of the learner: the recognition and accommodation of the need to enable learners to balance their thoughts, feelings and behaviours to generate positive self-affirmations.

The second clutch of studies focuses on curriculum organisation. Pedagogy which promotes the active and voluntary sharing of knowledge is one mechanism through which students can strengthen their internal locus of control and, thereby, their confidence (Ong et al. 2011). Voluntary knowledge sharing is neither automatic nor culturally 'normal' as shyness, fear of being wrong and language usage may all be barriers; but curriculum implementation which includes online communications, social interactions and out-of-hours activities is reported to contribute to increased knowledge sharing and consequent learner confidence. The recognition that learning is not some process of osmosis but that learners have to construct knowledge through their own cognitive efforts and that these efforts are influenced by beliefs about their capabilities to learn or perform at designated levels (Sakiz 2008) draws attention to the need to teach learning strategies which, in turn, improve self-confidence (Tuckman and Kennedy 2011). One corollary of learners being aware of the centrality of their role in learning is in the kinds of attributions they make to explain performance. Attributing success to effort and failure to lack of effort allows learners to adapt their study behaviour to achieve greater competence than do attributions of ability (Nokelainen, Tirri, and Merenti-Välimäki 2007). Viewing effort as leading to success, particularly when incrementally calibrated to progress extant achievement, enables both high and low-performing learners to improve their strategic behaviour for learning (Masui and De Corte 2005; Throndsen 2011; McClure et al. 2011).

Intervention programmes specifically designed to improve attainment in curricular areas such as mathematics (Falco, Crethar, and Bauman 2008) and science (Chang and Cheng 2008; Lockie and Van Lanen 2008; Susianna 2011) report improvements in self-confidence; a particularly important finding given the need for teachers to be pro-active in countering 
stereotypical perceptions of insurmountable difficulty and resulting loss of confidence when studying these subjects (Ziegler, Finsterwald, and Grassinger 2005). Other curricular areas are also reported to be effective in enhancing self-confidence. For example, religious education programmes which emphasise social interaction in the service of the community lessen the need for organised bureaucratic intervention. This increases the autonomy of people to be resources for each other; which is reported as improving self-confidence (Quezada 2004). Another catalyst for improved self-confidence appears to be in music education programmes (Hallam 2010). The improvements in self-confidence deriving from subject specific curriculum support extends to learners diagnosed as having (mild) learning difficulties (Mowschenson and Weintraub 2009). Programmes in which there is some curricular/academic ambience outwith formal schooling have also been viewed as improving self-confidence because of the perceived relevance of the learning activity for the real-life experiences of the learners (Cooper et al. 2010; Bergeron et al. 2010; Lee, Olszewski-Kubilius, and Peternel 2009; Downer 2007). What these studies centre on is the importance of substantive knowledge: the learner's grasp of domain knowledge together with strategies for learning within the particular domain provides a basis for learners to be clear about their own competence and agency.

\section{Implications of the Factors Influencing Self-Confidence}

Influences on self-confidence thus appear to originate in two sources: opportunities to confirm or enhance emotional wellbeing (which allow learners to talk about how they are thinking and feeling); and opportunities to enhance domain knowledge (which provides learners with additional resource with which to think). Improved self-regulation and increased substantive knowledge enable learners to take increasing responsibility for their own learning; and it is this scaffolded autonomy which promotes their self-confidence. While specified curricular content can be important, it will not become integrated into the learner's thinking unless the learner engages in cognitive and metacognitive processing (Marzano and Kendall 2007). This allows learners to examine their emotional responses to, the importance of, and efficacy for, particular content. Teachers therefore can usefully plan both sources into their curriculum designs.

\section{Conclusion}

The construct of self-confidence is a robust psychological element in our metacognitive repertoire. The construct is of importance to teachers because their interactions with learners necessitate awareness s of psychological functioning. It can be influenced only indirectly and, co-timeously, support of self-confidence is mediated through teachers' own reflections; which 
invoke substantive knowledge in a range of psychological topics. Therefore teachers' concern should focus on:

- The learner's development of knowledge which will interact with his/her academic selfconcept (developing expertise in any curricular area enhances academic self-concept for that domain and strengthens self-efficacy for particular targets within the domain)

- The learner's engagement in socially designed learning activities to promote nonacademic self-concept; as well as facilitating the development of knowledge

- Planning activities in which learners have to explain their reasoning and argue for the veracity of the evidence on which they make their claims

- Embedding self-regulative/metacognitive activities, routinely, into all lessons

- Engaging in dialogic feedback with learners so that learners become aware of the importance of taking control of their own learning

- Learners being socially aware but unconcerned with social comparisons

It is through engaging teachers' own reflections on the conceptual artefacts of what selfconfidence is, how self-confidence judgements are made and the susceptibility of self-confidence judgements to external factors, that they themselves can be better equipped to enable learners.

\section{References}

Alexander, P., H. Fives, M. Buehl, and J. Mulhern. 2002. "Teaching as persuasion." Teaching and Teacher Education no. 18 (7):795-813.

Andrews, R., and W. Harlen. 2006. "Issues in synthesizing research in education." Educational Research no. 48 (3):287-299.

Baumeister, R. 2005. "Rethinking self-esteem: why nonprofits should stop pushing self-esteem and start endorsing self-control." Stanford Social Innovation Review no. Winter:34-31.

Bereiter, C. 2002. Education and Mind in the Knowledge Age. Mahwah, NJ: Lawrence Erlbaum Associates.

Bergeron, C., C. Sharp, S. Wilson, T. Yeshanew, B. Styles, and P. Rudd. 2010. The Double Club Evaluation. London: NFER.

Block, M., A. Taliaferro, N. Harris, and J. Krause. 2010. "Using self-efficacy theory to facilitate inclusion in general physical education." Journal of Physical Education, Recreation and Dance no. 81 (3):43-46.

Boekaerts, M., and J. Rozendaal. 2010. "Using multiple calibration indices in order to capture the complex picture of what affects students' accuracy of feeling of confidence." Learning and Instruction no. 20 (5):372-382.

Bong, M., and E. Skaalvik. 2003. "Academic self-concept and self-efficacy: how different are they really?" Educational Psychology Review no. 15 (1):1-40.

Brewer, W., C Sampaio, and M. Barlow. 2005. "Confidence and accuracy in the recall of deceptive and nondeceptive sentences." Journal of Memory and Language no. 52 (4):618-627.

Briñol, P., K. DeMarree, and R. Petty. 2010. "Processes by which confidence (vs. doubt) influences the self." In The Uncertain Self: A Handbook of Perspectives from Social and Personality Psychology, edited by K. Arkin, K. Oleson and P. Carroll, 13-35. NewYork: PsychologyPress.

Briñol, P., and R. Petty. 2009. "Persuasion: insights from the self-validation hypothesis." In Advances in Experimental Social Psychology, edited by M. Zanna, 69-118. Burlington: Academic Press. 
Brunner, M., U. Keller, C. Dierendonck, M. Reichert, S. Ugen, A. Fischbach, and R. Martin. 2010. "The structure of academic self-concepts revisited: The nested Marsh/Shavelson model." Journal of Educational Psychology no. 102 (4):964-981.

Burson, K., R. Larrick, and J. Klayman. 2006. "Skilled or unskilled, but still unaware of it: how perceptions of difficulty drive miscalibration in relative comparisons." Journal of Personality and Social Psychology no. 90 (1):60-77.

Caprara, G., R. Fida, M. Vecchione, G. Del Bove, G. Vecchio, C. Barbaranelli, and A. Bandura. 2008. "Longitudinal analysis of the role of perceived self-efficacy for self-regulated learning in academic continuance and achievement." Journal of Educational Psychology no. 100 (3):525-534.

Chang, C., and W. Cheng. 2008. "Science achievement and students' self-confidence and interest in science: A Taiwanese representative sample study." International Journal of Science Education no. 30 (9):1183-1200.

Cooper, H., A. Allen, E. Patall, and A. Dent. 2010. "Effects of full-day kindergarten on academic achievement and social development." Review of Educational Research no. 80 (1):34-70.

Correll, J., S. Spencer, and M. Zanna. 2004. "An affirmed self and an open mind: Self-affirmation and sensitivity to argument strength." Journal of Experimental Social Psychology no. 40 (3):350-356.

Craig, C. 2007. Creating Confidence. Glasgow: Centre for Confidence and Well-being.

Cramer, R., T. Neal, and S. Brodsky. 2009. "Self-efficacy and confidence: Theoretical distinctions and implications for trial consultation." Consulting Psychology Journal: Practice and Research no. 61 (4):319-334.

De Vries, P., C. Midden, and D. Bouwhuis. 2003. "The effects of errors on system trust, selfconfidence, and the allocation of control in route planning." International Journal of HumanComputer Studies no. 58 (6):719-735.

Deng, Z. 2004. "The role of theory in teacher preparation: an analysis of the concept of theory application." Asia-Pacific Journal of Teacher Education no. 32 (2):143-157.

Downer, A. 2007. "The National Literacy Strategy Sight Recognition Programme implemented by teaching assistants: A precision teaching approach." Educational Psychology in Practice no. 23 (2):129-143.

Dunlosky, J., and K. Rawson. 2012. "Overconfidence produces underachievement: Inaccurate self evaluations undermine students' learning and retention." Learning and Instruction no. 22 (4):271-280.

Efklides, A. 2011. "Interactions of metacognition with motivation and affect in self-regulated learning: the MASRL Model." Educational Psychologist no. 46 (1):6-25.

Ehrlinger, J., and D. Dunning. 2003. "How chronic self-views influence (and potentially mislead) estimates of performance." Journal of Personality and Social Psychology no. 84 (1):5-17.

Recommendation of the European Parliament and of the Council on key competences for lifelong learning. Official Journal L 394 of 30.12.2006.

European Commission. 2012. Assessment of Key Competences in initial education and training: Policy Guidance. Strasbourg.

Falco, L., H. Crethar, and S. Bauman. 2008. "Skill-Builders: improving middle school students' selfbeliefs for learning mathematics." Professional School Counseling no. 11 (4):229-235.

Ferkany, M. 2008. "The educational importance of self-esteem." Journal of Philosophy of Education no. 42 (1):119-132.

Ferla, J., M. Valcke, and Y. Cai. 2009. "Academic self-efficacy and academic self-concept: Reconsidering structural relationships." Learning and Individual Differences no. 19 (4):499-505.

Fink, A. 2010. Conducting Research Literature Reviews. London: Sage.

Garger, J., M. Thomas, and P. Jacques. 2010. "Early antecedents to students' expected performance." International Journal of Educational Management no. 24 (2 ):129 - 138.

Goldstone, R., and S. Day. 2012. "Introduction to "New Conceptualizations of Transfer of Learning"." Educational Psychologist no. 47 (3):149-152.

Grassi, E., D. Hanley, and D. Liston. 2004. "Service-Learning: an innovative approach for second language learners." Journal of Experiential Education no. 27 (1):87-110.

Guérin, E., I. Arcand, and N. Durand-Bush. 2010. "A view from the inside: an in-depth look at a female university student's experience with a Feel-Based Intervention to enhance selfconfidence and self-talk." The Qualitative Report no. 15 (5):1058-1079. 
Hagger, M., C. Wood, C. Stiff, and N. Chatzisarantis. 2010. "Ego depletion and the strength model of self-control: A meta-analysis." Psychological Bulletin no. 136 (4):495-525.

Hakkarainen, Kai. 2009. "A knowledge-practice perspective on technology-mediated learning." International Journal of Computer-Supported Collaborative Learning no. 4 (2):213-231. doi: 10.1007/s11412-009-9064-x.

Hallam, S. 2010. "The power of music: Its impact on the intellectual, social and personal development of children and young people." International Journal of Music Education no. 28 (3):269-289.

Hattie, J., and M. Gan. 2011. "Instruction based on feedback." In Handbook of Research on Learning and Instruction, edited by R. Mayer and P. Alexander, 249-271. London: Routledge.

Hertzog, C., J. Price, and J. Dunlosky. 2008. "How is knowledge generated about memory encoding strategy effectiveness?" Learning and Individual Differences no. 18 (4):430-445.

Hodges, T., and J. Harter. 2005. "A review of the theory and research underlying the StrengthsQuest Program for Students." Educational Horizons no. 83 (3):190-201.

Horry, R., M. Palmer, M. Sexton, and N. Brewer. 2012. "Memory conformity for confidently recognized items: The power of social influence on memory reports." Journal of Experimental Social Psychology no. 48 (3):783-786.

Jakobsson, A. 2006. "Students' self-confidence and learning through dialogues in a net-based environment." Journal of Technology and Teacher Education no. 14 (2):387-405.

John, P. 2005. "The contribution of volunteering, trust, and networks to educational performance." Policy Studies Journal no. 33 (4):635-656. doi: 10.1111/j.1541-0072.2005.00136.x.

Kamtsios, S., and E. Karagiannopoulou. 2012. "Conceptualizing students' academic hardiness dimensions: a qualitative study." European Journal of Psychology of Education:1-17. doi: 10.1007/s10212-012-0141-6.

Kelly, M., and R. Bluestone-Miller. 2009. "Working on What Works (WOWW): coaching teachers to do more of what's working." Children \& Schools no. 31 (1):35-38.

Kleitman, S. 2008. Metacognition in the Rationality Debate: self-confidence and its calibration. Saarbrücken, Germany: VDM Verlag Dr Müller.

Kleitman, S., and T. Moscrop. 2010. "Self-confidence and academic achievements in primary-school children: their relationships and links to parental bonds, intelligence, age, and gender." In Trends and Prospects in Metacognition Research, edited by A. Efklides and P. Misailidi, 293-326. US: Springer.

Kleitman, S., and L. Stankov. 2007. "Self-confidence and metacognitive processes." Learning and Individual Differences no. 17 (2):161-173.

Koriat, A. 2008. "Subjective confidence in one's answers: The consensuality principle." Journal of Experimental Psychology: Learning, Memory, and Cognition no. 34 (4):945-959.

- - - 2012. "The self-consistency model of subjective confidence." Psychological Review no. 119 (1):80113.

Kristjánsson, K. 2010. The Self and its Emotions: Cambridge University Press.

Kröner, S., and A. Biermann. 2007. "The relationship between confidence and self-concept - Towards a model of response confidence." Intelligence no. 35 (6):580-590.

Kruglanski, A. 1990. "Lay epistemic theory in social-cognitive psychology." Psychological Inquiry no. 1 (3):181-197.

Kruglanski, A., A. Raviv, D. Bar-Tal, A. Raviv, K. Sharvit, S. Ellis, R. Barr, A. Pierro, and L. Mannetti. 2005. "Says who? epistemic authority effects in social judgment." In Advances in Experimental Social Psychology, edited by M. P. Zanna, 345-392. San Diego, CA: Elsevier.

Larrick, R., K. Burson, and J. Soll. 2007. "Social comparison and confidence: When thinking you're better than average predicts overconfidence (and when it does not)." Organizational Behavior and Human Decision Processes no. 102 (1):76-94.

Lee, J. 2009. "Universals and specifics of math self-concept, math self-efficacy, and math anxiety across 41 PISA 2003 participating countries." Learning and Individual Differences no. 19 (3):355-365.

Lee, S., P. Olszewski-Kubilius, and G. Peternel. 2009. "Follow-Up with Students After 6 Years of Participation in Project EXCITE." Gifted Child Quarterly no. 53 (2):137-156.

Lloyd, C., S. Bruce, and K. Mackintosh. 2012. "Working on what works: enhancing relationships in the classroom and improving teacher confidence." Educational Psychology in Practice no. 28 (3):241256. 
Lockie, N., and R. Van Lanen. 2008. "Impact of the supplemental instruction experience on Science SI Leaders." Journal of Developmental Education no. 31 (3):2-4, 6, 8, 10-12, 14.

Loseman, A., and K. Van Den Bos. 2012. "A self-regulation hypothesis of coping with an unjust world: ego-depletion and self-affirmation as underlying aspects of blaming of innocent victims." Social Justice Research no. 25 (1):1-13. doi: 10.1007/s11211-012-0152-0.

Lüftenegger, M., B. Schober, R. Van De Schoot, P. Wagner, M. Finsterwald, and C. Spiel. 2012. "Lifelong learning as a goal - Do autonomy and self-regulation in school result in well prepared pupils?" Learning and Instruction no. 22 (1):27-36.

Maggioni, L., and M. Parkinson. 2008. "The role of teacher epistemic cognition, epistemic beliefs, and calibration in instruction." Educational Psychology Review no. 20:445-461.

Marsh, H., U. Trautwein, O. Lüdtke, O. Köller, and J. Baumert. 2006. "Integration of multidimensional self-concept and core personality constructs: construct validation and relations to well-being and achievement." Journal of Personality no. 74 (2):403-456.

Marzano, R., and J. Kendall. 2007. The New Taxonomy of Educational Objectives. Thousand Oaks, CA: Corwin Press.

Masui, C., and E. De Corte. 2005. "Learning to reflect and to attribute constructively as basic components of self-regulated learning." British Journal of Educational Psychology no. 75 (3):351372. doi: 10.1348/000709905×25030.

McClure, J., L. Meyer, J. Garisch, R. Fischer, K. Weir, and F. Walkey. 2011. "Students' attributions for their best and worst marks: do they relate to achievement?" Contemporary Educational Psychology no. 36 (2):71-81.

Mitchum, A., and C. Kelley. 2010. "Solve the problem first: Constructive solution strategies can influence the accuracy of retrospective confidence judgments." Journal of Experimental Psychology: Learning, Memory, and Cognition no. 36 (3):699-710. doi: 10.1037/a0019182.

Moore, D., and P. Healy. 2008. "The trouble with overconfidence." Psychological Review no. 115 (2):502517.

Mowschenson, J., and R. Weintraub. 2009. "Beyond special education: a new vision of academic support." Phi Delta Kappan no. 90 (10):751-755.

Mulnix, J. 2012. "Thinking critically about critical thinking." Educational Philosophy and Theory no. 44 (5):464-479.

Nokelainen, P., Kirsi Tirri, and H. Merenti-Välimäki. 2007. "Investigating the influence of Attribution Styles on the development of mathematical talent." Gifted Child Quarterly no. 51 (1):64-81.

Ong, H., P. Yeap, S. Tan, and L. Chong. 2011. "Factors influencing knowledge sharing among undergraduate students: A Malaysian perspective." Industry and Higher Education no. 25 (2):133-140.

Park, C, and J. Hyun. 2006. Comparison of two learning models for collaborative e-learning. Paper read at 1st International Conference on Technologies for E-Learning and Digital Entertainment: Hangzhou, People's Republic of China, April 16-19.

Pazy, A. 2004. "Updating in response to the experience of lacking knowledge." Applied Psychology no. 53 (3):436-452.

Petty, R., P. Briñol, Z. Tormala, and D. Wegener. 2007. "The role of metacognition in social judgment " In Social psychology: Handbook of Basic Principles (2nd ed.), edited by A. Kruglanski and E. Higgins, 254-284. New York, US: Guilford Press.

Petty, R., P. Briñol, and Z. Tormala. 2002. "Thought confidence as a determinant of persuasion: The self-validation hypothesis." Journal of Personality and Social Psychology no. 82 (5):722-741. doi: 10.1037/0022-3514.82.5.722.

Powell, L., M. Gilchrist, and J. Stapley. 2008. "A journey of self-discovery: an intervention involving massage, yoga and relaxation for children with emotional and behavioural difficulties attending primary schools." European Journal of Special Needs Education no. 23 (4):403-412.

Prat-Sala, M., and P. Redford. 2011. "Writing essays: does self-efficacy matter? The relationship between self-efficacy in reading and in writing and undergraduate students' performance in essay writing." Educational Psychology no. 32 (1):9-20.

Puncochar, J., and P. Fox. 2004. "Confidence in individual and group decision making: when "two heads" are worse than one." Journal of Educational Psychology no. 96 (3):582-591. 
Putwain, D., P. Sander, and D. Larkin. 2012. "Academic self-efficacy in study-related skills and behaviours: relations with learning-related emotions and academic success." British Journal of Educational Psychology:n/a-n/a. doi: 10.1111/j.2044-8279.2012.02084.x.

Quezada, T. 2004. "Faith-based organizing for school improvement in the Texas borderlands: a case study of the Texas Alliance School Initiative." The School Community Journal no. 14 (1):7-38.

Risko, V., and D. Walker-Dalhouse. 2009. "Parents and teachers: talking with or past one another-or not talking at all?" The Reading Teacher no. 62 (5):442-444. doi: 10.1598/rt.62.5.7.

Roebers, C. 2002. "Confidence judgments in children's and adult's event recall and suggestibility." Developmental Psychology no. 38 (6):1052-1067.

Sakiz, G. 2008. An Interview with Dale Schunk. In Part of a special issue entitled Metacognition, selfregulation, and self-regulated learning.

Sax, L., A. Bryant, and C. Harper. 2005. "The differential effects of student-faculty Interaction on college outcomes for women and men." Journal of College Student Development no. 46 (6):642657.

Schwarz, S., and C. Roebers. 2006. "Age differences in the effects of social influence on children's eyewitness performance and their metacognitive monitoring." Journal of Experimental Child Psychology no. 94 (3):229-248.

Sedikides, C., and A. Gregg. 2007. "Portraits of the Self." In The Sage Handbook of Social Psychology, edited by M. Hogg and J. Cooper, 93-122. London: Sage Publications.

Seevers, B. , F. Hodnett, and D. Van Leeuwen. 2011. "Findings of 4-H Impact Studies in Six Western States." Journal of Extension no. 49 (4):start p.10.

Sherman, D. , and G. Cohen. 2006 "The psychology of self-defense: self-affirmation theory." In Advances in experimental social psychology edited by M. Zanna, 183-242. San Diego, CA: Academic Press.

Shi, J., Y. Li, and X Zhang. 2008. "Self-concept of gifted children aged 9 to 13 years." Journal for the Education of the Gifted no. 31 (4):481-499.

Skinner, E. 1996. "A guide to constructs of control." Journal of Personality and Social Psychology no. 71 (3):549-570. doi: 10.1037/0022-3514.71.3.549.

Soll, J., and J. Klayman. 2004. "Overconfidence in interval estimates." Journal of Experimental Psychology: Learning, Memory, and Cognition no. 30 (2):299-314.

Stajkovic, A. 2006. "Development of a core confidence-higher order construct." Journal of Applied Psychology no. 91 (6):1208-1224.

Stankov, L., and S. Kleitman. 2008. "Processes on the borderline between cognitive abilities and personality: confidence and its realism." In The Sage Handbook of Personality Theory and Assessment, edited by G. Boyle, G. Matthews and D. Saklofske, 541-555. London: Sage.

Stankov, L., and J. Lee. 2008. "Confidence and cognitive test performance." Journal of Educational Psychology no. 100 (4):961-976.

Stankov, L., J. Lee, W. Luo, and D. Hogan. 2012. "Confidence: A better predictor of academic achievement than self-efficacy, self-concept and anxiety?" Learning and Individual Differences

Stankov, L., J. Lee, and I. Paek. 2009. "Realism of confidence judgments." European Journal of Psychological Assessment no. 25 (2):123-130.

Stankov, L., G. Pallier, V. Danthiir, and S. Morony. 2012. "Perceptual underconfidence: A conceptual illusion?" European Journal of Psychological Assessment no. 28 (3):190-200.

Stanovich, K., and R. West. 1998. "Individual differences in rational thought." Journal of Experimental Psychology: General no. 127 (2):161-188. doi: 1.

- - - 1999. "Discrepancies between normative and descriptive models of decision making and the understanding/acceptance principle." Cognitive Psychology no. 38 (3):349-385.

- - - 2000. "Individual differences in reasoning: Implications for the rationality debate?" Behavioral and Brain Sciences no. 23 (05):645-665.

Stirin, K., Y. Ganzach, A. Pazy, and D. Eden. 2012. "The effect of perceived advantage and disadvantage on performance: the role of external efficacy." Applied Psychology no. 61 (1):8196.

Story, A. 2004. "Self-esteem and self-certainty: a mediational analysis." European Journal of Personality no. 18 (2):115-125. 
Strauss, Sidney. 1993. "Teachers' pedagogical content knowledge about children's minds and learning: Implications for teacher education." Educational Psychologist no. 28 (3):279-290. doi: $10.1207 /$ s15326985ep2803_7.

Susianna, N. 2011. "The Chemistry teaching program for developing the senior high school students' entrepreneurial attitudes." US-China Education Review B 7 909-923.

Thomas, C., and S. Gadbois. 2007. "Academic self-handicapping: The role of self-concept clarity and students' learning strategies." British Journal of Educational Psychology no. 77 (1):101-119.

Throndsen, I. 2011. "Self-regulated learning of basic arithmetic skills: A longitudinal study." British Journal of Educational Psychology no. 81 (4):558-578.

Tofthagen, R., and L. Fagerstrøm. 2010. "Rodgers' evolutionary concept analysis - a valid method for developing knowledge in nursing science." Scandinavian Journal of Caring Sciences no. 24:21-31

Tormala, Z., D. Rucker, and C. Segers. 2008. "When increased confidence yields increased thought: a confidence-matching hypothesis." Journal of Experimental Social Psychology no. 44:141-147.

Tuckman, B., and G. Kennedy. 2011. "Teaching learning strategies to increase success of first-term college students." The Journal of Experimental Education no. 79 478-504.

Usher, E., and F. Pajares. 2006. "Inviting confidence in school: invitations as a critical source of the academic self-efficacy beliefs of entering middle school students " Journal of Invitational Theory and Practice no. 12:7-10.

Valentine, J., D. DuBois, and H. Cooper. 2004. "The relation between self-beliefs and academic achievement: a meta-analytic review." Educational Psychologist no. 39 (2):111-133.

Van De Gaer, E., A. Grisay, W. Schulz, and E. Gebhardt. 2012. "The Reference Group Effect: An Explanation of the Paradoxical Relationship Between Academic Achievement and SelfConfidence Across Countries." Journal of Cross-Cultural Psychology. doi: $10.1177 / 0022022111428083$.

Weary, G., S. Tobin, and J. Edwards. 2010. "The causal uncertainty model revisited." In Handbook of the Uncertain Self, edited by R. Arkin, K. Oleson and P. Carroll, 78-100. Mahwah, NJ: Lawrence Erlbaum.

Woodman, T., S. Akehurst, L. Hardy, and S. Beattie. 2010. "Self-confidence and performance: A little self-doubt helps." Psychology of Sport and Exercise no. 11 (6):467-470.

Yang, M., and D. Carless. 2012. "The feedback triangle and the enhancement of dialogic feedback processes." Teaching in Higher Education:1-13. doi: 10.1080/13562517.2012.719154.

Yaniv, I, S Choshen-Hillel, and M. Milyavsky. 2009. "Spurious consensus and opinion revision: Why might people be more confident in their less accurate judgments?" Journal of Experimental Psychology: Learning, Memory, and Cognition no. 35 (2):558-563. doi: 10.1037/a0014589.

Ziegler, A., M. Finsterwald, and R. Grassinger. 2005. "Predictors of learned helplessness among average and mildly gifted girls and boys attending initial high school Physics instruction in Germany." Gifted Child Quarterly no. 49 (1):7-18.

Zimmerman, B. 2008. "Investigating self-regulation and motivation: historical background, methodological developments, and future prospects." American Educational Research Journal no. 45:166 -183.

\section{7,411 words}

